\title{
Electrospray Mass Spectrometry Study of Tiopronin Monolayer-Protected Gold Nanoclusters
}

\author{
Anthony P. Gies, ${ }^{*}$ David M. Hercules, Aren E. Gerdon, and David E. Cliffel
}

Department of Chemistry, Vanderbilt University, Nashville, TN 37235

E-mail:a.gies@ vanderbilt.edu

Journal of the American Chemical Society: June 4, 2006

TITLE RUNNING HEAD: ESI-TOF MS Study of MPCs.

CORRESPONDING AUTHOR FOOTNOTE: Address reprint requests to Anthony P. Gies, Department of Chemistry, Vanderbilt University, 7330 Stevenson Center, Nashville, TN 37235. Telephone: (615) 343-5980. E-mail: a.gies@ vanderbilt.edu 


\section{Experimental}

$U V$-Visible Spectroscopy

UV-visible spectroscopy scans (Figure S1), from 200 to $800 \mathrm{~nm}$, were taken of aqueous solutions in a 1-cm quartz cell and recorded with a Cary 100 BioSpectrophotometer.

\section{Transmission Electron Microscopy}

Transmission electron microscopy (TEM) images (Figure S2) were taken on a Philips CM20 instrument after applying aqueous MPC samples to Formvar-coated 200-mesh copper grids (Ted Pella). The microscope was operated at $200 \mathrm{keV}$ with magnification in the range of 150540,000x. 


\section{FIGURE CAPTIONS:}

Figure S1. UV-visible absorbance of auric acid $(0.13 \mathrm{mM})$, auric acid $(0.13 \mathrm{mM}) /$ tiopronin $(0.43 \mathrm{mM})$ mixture, auric acid/tiopronin mixture after the addition of sodium borohydride and purification, yielding MPCs. MPCs were diluted in half to obtain an appropriate absorbance spectrum. Broad absorbance, increasing exponentially with decreasing wavelength, is typical of MPCs.

Figure S2. TEM image of tiopronin MPC, showing spherical clusters with an average diameter of $3.2 \pm 1.0 \mathrm{~nm}$ and an estimated average composition of $\mathrm{Au}_{617} \mathrm{Tiop}_{247}$. 
Figure S1.

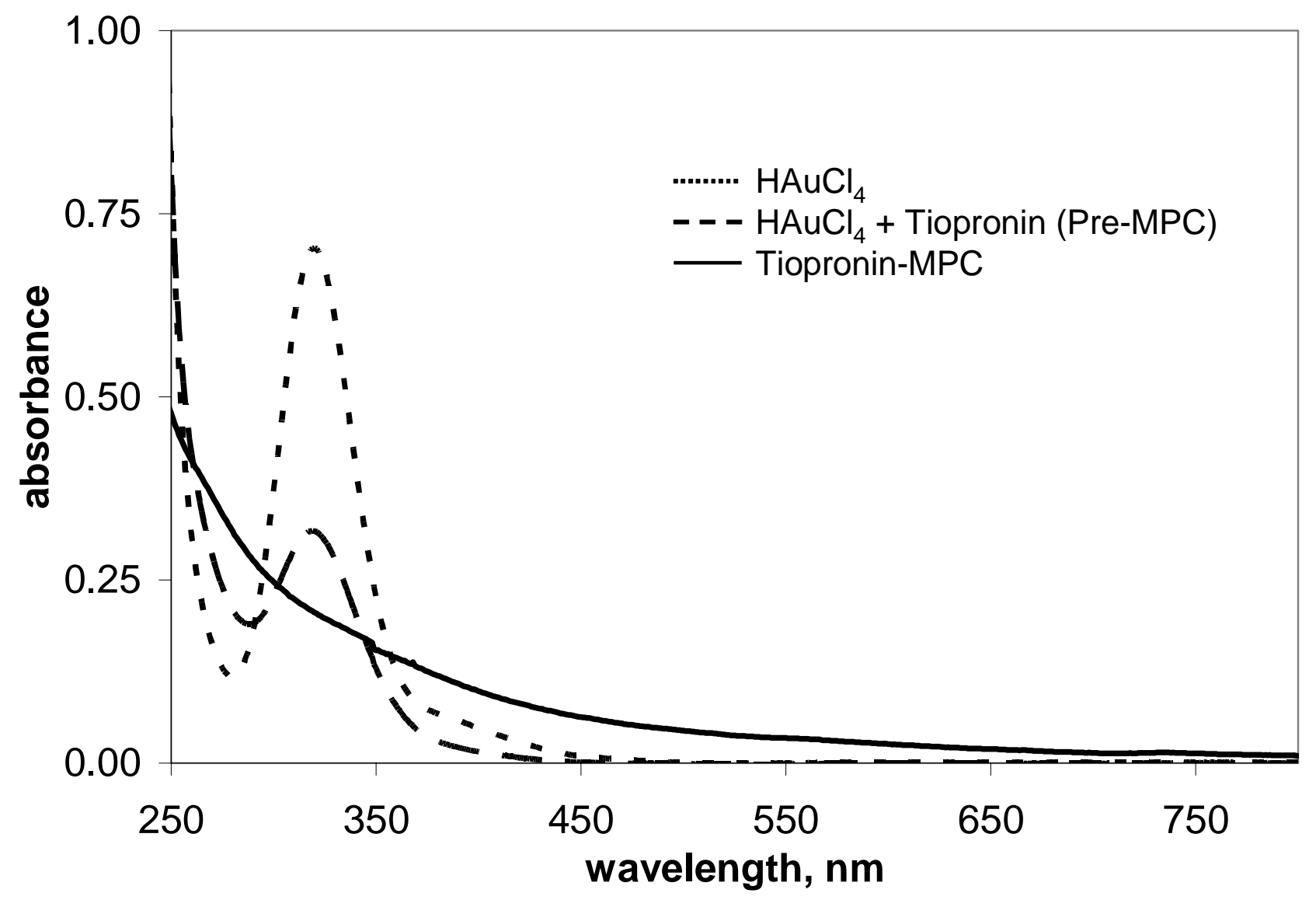


Figure S2.

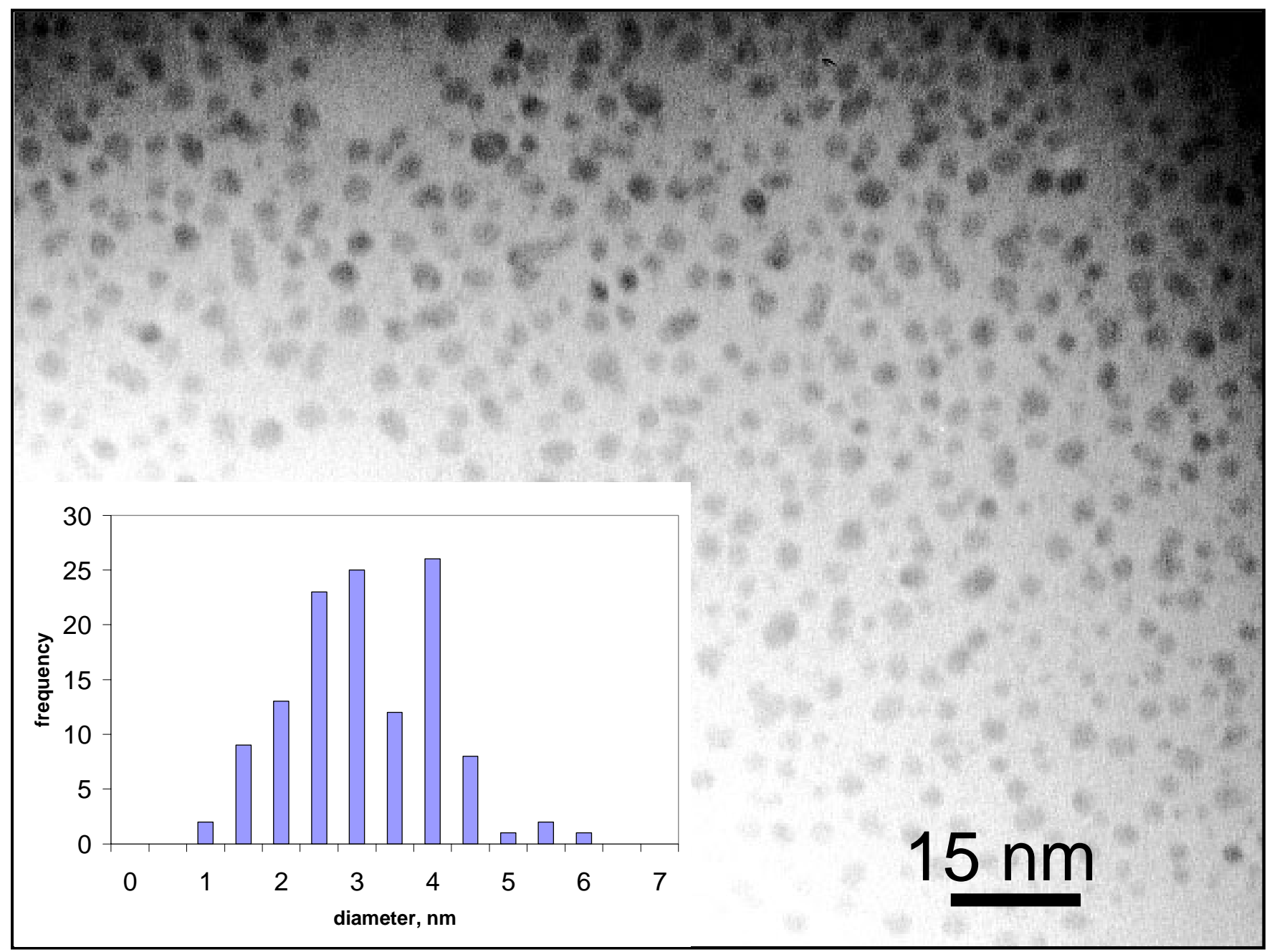

